Article

\title{
Understanding the Sustainable Usage Intention of Mobile Payment Technology in Korea: Cross-Countries Comparison of Chinese and Korean Users
}

\author{
Xin $\operatorname{Lin}^{1,2}$, RunZe $\mathrm{Wu}^{3}$, Yong-Taek Lim ${ }^{1, *}$, Jieping Han ${ }^{2, *}$ and Shih-Chih Chen ${ }^{4, *(1)}$ \\ 1 Department of International Trade, Kunsan National University, Kunsan 54150, Korea; linxin@neepu.edu.cn \\ 2 School of Economics and Management, Northeast Electric Power University, Jilin 132012, China \\ 3 College of Business, Jiaxing University, Jiaxing 314001, China; wu3140025@163.com \\ 4 Department of Information Management, National Kaohsiung University of Science and Technology, \\ Kaohsiung 824, Taiwan \\ * Correspondence: lyt@kunsan.ac.kr (Y.-T.L.); hanjieping@neepu.edu.cn (J.H.); scchen@nkust.edu.tw (S.-C.C.)
}

Received: 8 August 2019; Accepted: 1 October 2019; Published: 8 October 2019

check for updates

\begin{abstract}
Mobile payment (m-payment) enables consumers to perform their payment tasks via a mobile technology platform. In this study, we summarized, evaluated, and expanded upon the literature about m-payment usage intention by synthetically integrating the advantages of three information systems theories into an integrated model, which details the complementary relationship between the objective measures, subjective perception of m-payment services, and m-payment technology-task fit characteristics. Based on a sample of 908 individuals in two different Kakaopay user groups (467 Chinese Kakaopay users in Korea and 441 local Korean Kakaopay users) and the three-model integrated optimization, we integrated the unified theory of acceptance and use of technology model (UTAUT), the information systems success model (D\&M ISS), and the task-technology fit model (TTF), considering moderating variables (Chinese and Korea experienced consumers) and multi-group analysis. We chose the factors influencing Chinese and Korean consumers' usage intention as the research objects, and ultimately achieved our purpose of more accurately predicting consumer behavior patterns to expand the scale of potential Chinese consumers. The empirical results theoretically contribute to academic and practical solutions for the Korean m-payment product and help technology suppliers to stimulate the sustainable growth of Korean mobile payment consumer groups in Korea.
\end{abstract}

Keywords: mobile payment; UTAUT; D\&M ISS; TTF; usage intention

\section{Introduction}

The world economy has a three-tiered world pattern, with the European Economic Area, the Free Trade Area of the Americas, and Asia-Pacific Economic Cooperation (APEC) as the centers. Judging by the South Korean and global trade cycle data, from January 2007 to January 2013, the Korean exports indicator was shown to be a leading indicator of global trade. Therefore, the Korean exports indicator is called a canary in the coal mine, as a barometer of global economic growth [1].

According to the data compiled by Statistics Korea in 2018, among all the South Korean export growth (SKEG) Indicators, the total amount of Korean online shopping transactions increased to \$0.096 trillion USD (ranked fifth in the Organization for Economic Co-operation and Development (OECD) nations), generating 6.27\% of the Korean GDP (\$1.53 trillion USD), showing significantly more sustainable characteristics than the ratio of Korean traditional manufacturing trades, such as the 
automotive manufacturing trade $(4.0 \%)$ and the shipment trade (1.3\%). In 2018, the growth rate of Korean mobile payment, which has significantly contributed to the sustainability of Korean economic growth, was 31.7\% [2], far exceeding Korea's 2.7\% gross domestic product (GDP) growth in 2018 [3]. The sustainable growth of Korean mobile payment (m-payment) as an essential part of the SKEG indicators is crucial for the sustainable economic growth of Korea and the world.

Relevant data from 2018 showed that compared with the two larger major e-commerce markets, the United States and Europe, China's electronic commerce sales reached $\$ 634$ billion USD, which has become the highest globally. The global e-commerce sales of 2019 are expected to exceed the threshold of $\$ 2$ trillion USD, and China's e-commerce market is expected to remain ahead until 2023. Purchasing power has begun to shift from the United States and Europe to China and Southeast Asia, driven by an increasing number of Asian purchasers acquiring e-commerce from the rising purchasing power and greater Internet penetration, especially on mobile devices. Data from the China Ministry of Commerce revealed that by the end of 2018, the value of China's e-commerce market accounted for $\$ 633.9$ billion USD, and it has been the biggest electronic commerce market globally for several consecutive years [4].

From the above-mentioned literature, the following conclusion can be drawn: Considering the unique geographical advantage and driven by the higher e-commerce penetration rate, Korean m-payment service suppliers should realize that simply preserving the current Korean customers is insufficient; it is necessary to stimulate the elements influencing the usage intention of the Chinese consumer group.

In this study, we considered Korea's largest mobile payment platform, Kakaopay, and we comprehensively studied all the factors affecting the sustainable development of Korean m-payment. As a provider of mobile payment and digital wallet services, Kakaopay (Kakao Co., Ltd., Seoul, Korea) allows consumers to perform mobile payment tasks using Near Field Communication (NFC) and two-dimensional codes [5]. On 22 January 2016, by establishing the Kakao online bank and issuing debit cards, Kakao expanded to online financial transactions. On 21 February 2017, Kakaopay obtained \$200 million USD from Ant Financial of Alibaba Co., Ltd. (Hangzhou, China). In April 2017, Kakaopay was launched separately to manage the payment transactions. Kakaopay broke through the barrier of 10 million users within 20 months. On 21 May 2019, Korea government legally permitted Kakaopay to develop m-payment services abroad [6]. Predictably, Kakaopay will provide joint services support with Alipay to service 450 million Chinese and Korean consumers' m-payment requirements in the foreseeable future. Facing the exponentially increasing number of Chinese consumers, Korean m-payment suppliers should focus on core factors influencing the Chinese and Korean consumers' m-payment system usage intention. Whether the Korean m-payment system can successfully survive is mostly influenced by vital core factors, such as user satisfaction, performance expectancy (PE), and compatibility between the technical features and task demands [7].

Due to the limited research on the unified theory of acceptance and use of technology model (UTAUT) for mobile payment, our research is one of the few attempts to extend UTAUT from the perspective of multi-group and multi-model integration. Various researchers have sought the factors determining usage intention [8,9]. However, these elements have rarely been integrated into a comprehensive model. These studies in Asia have provided enough evidence in the research field of Korean mobile payment technology, with considerable empirical research literature published for the Chinese and Korean populations [10]. To address the lack of research in related fields, we combined the information systems success model (D\&M ISS) and the task-technology fit model (TTF) with UTAUT, and used this integrated model as the conceptual model presented here. This combined model compensates for the respective limitations of the three individual models and considers the subjective and objective factors. We also considered the moderator variable of the Chinese and Korean experience and multi-group analysis to enhance the multi-model integration method.

This research provides two significant contributions. Firstly, from a conceptual perspective, we expand upon previous research on the usage willingness in relation to Korean m-payment by suggesting that D\&M ISS and TTF are critical components of UTAUT. Compared with traditional 
single-model analysis, this three-dimensional integration model enables the systematic examination of the factors determining consumers' acceptance of m-payment solutions from a more comprehensive viewpoint. Secondly, the conclusions drawn in this study can provide a contrastive perspective on the moderating influence of Chinese and Korean consumers' experience on the Kakaopay usage intention. For attracting potential Chinese adopters, identifying the similarities and differences between the Korean and Chinese consumers is necessary. Generally, given the background of the exponential growth of 5G Internet of Things (IoT), an integrated and contrastive perspective is conducive to follow-up research, expanding the scope of research to the use of elements affecting global m-payment willingness.

Considering the extensive cooperation between China and South Korea in the mobile payment industry, which began in early 2017, we studied the elements influencing Korean m-payment users' usage intention (Chinese Kakaopay users in Korea and local Korean Kakaopay users) as the research objects. By comparing the differences between the two countries' users, we aimed to stimulate the core factors which influence the Chinese consumers' usage intention in Korea, and to provide the necessary theoretical foundation and practical preparation for larger-scale China-Korea sustainable mobile payment market cooperation.

The remainder of this paper is organized as follows. Section 2 presents related literature on the three information system models of Korean mobile payment usage intention; Section 3 states the research design, research hypotheses and the proposed model; Section 4 reports the data collection, analysis, and results, including survey design and sample selection; and the final section presents the research findings, research contributions, actual impact, and future research recommendations.

\section{Background and Literature Review}

\subsection{Mobile Payment}

M-payment has been explained as any payment transaction that is explicitly initiated, conferred, and confirmed by a mobile terminal [11]. A mobile payment transaction is usually conducted remotely via preferential rate SMS, wireless application protocol billing, cellular networks, direct subscriber billing, and direct credit cards. Therefore, m-payments can efficiently handle financial transactions through mobile networks, as well as through several wireless skills, such as near field communication (NFC) and radio frequency identification (RFID) [12]. M-payment technology has grown extensively around the world, and its spreading power and cross-border influence are increasing. Digital wallets, also called "electronic wallets", refer to the mobile equipment or online business transaction that supports a consumer when conducting electronic business [13]. Consumers can use a smartphone to purchase something at an off-line store. An individual's bank account can be connected to the digital wallet, and the vouchers can be wirelessly transmitted to the seller's terminals through NFC.

In 2018, mobile payment technology accounted for $4.6 \%$ of the global GDP, a contribution worth $\$ 3.9$ trillion USD in economic value [14]. Wang [15] reported that cross-border m-payment had a pivotal role in promoting international trade, showing that systemized m-payment services would encourage the integration of m-payment and settlement in the Asia-Pacific region, and had even enabled the integration and sustainable development of consumer markets in Southeast Asia.

However, not all customers have accepted mobile payment as an important service [16]. Therefore, academics have been focusing on determining the factors influencing usage intention. Chun [17] stated that when arguments arose between customers and companies in electronic businesses, responsibility allocation was crucial to the sustainability of e-commerce. By analyzing the market reactions to Samsung Pay and Apple Pay, Son and Kim [18] revealed that technology administration policies could confirm the sustainability of fast-changing technological progress. Other authors have used various typical structural equation models, including the technology acceptance model (TAM), UTAUT, and the unified theory of acceptance and use of technology 2 (UTAUT2), as the basic structures in their research to identify any factor that can affect m-payment usage willingness [11,19]. 


\subsection{UTAUT}

Eight main technology acceptance relevant models were unified and incorporated in UTAUT by Venkatesh et al. [20]. UTAUT also posits four core variables that are the factors determining usage willingness in relation to the adoption of technology: Performance expectancy (PE), effort expectancy (EE), social influence (SI), and facilitating conditions (FC). Additionally, it postulates the role of four vital moderating elements [20].

UTAUT has been studied from different research perspectives of behavior usage intention and technology adoption. Proposed as an extension to TAM [21], UTAUT [20] was used to evaluate the importance of increasingly commonplace information system technology in usage intention. According to the UTAUT model, the usage intention is influenced by PE, EE, SI, and FC. UTAUT has been applied to identify and examine variables that affect the usage intention of mobile commerce acceptance [22,23], mobile shopping [24,25] and mobile banking usage adoption [26,27]. Palau-Saumell [28] reported that the consumer experience has moderating effects on the hypothesis of the independent elements of the task-technology fit, user satisfaction, PE, EE, SI, FC, and m-payment usage intention. A survey on the potential adoption of mobile payments found that user experience is a moderator of their intention to switch mobile platforms [29], integrating the experience into D\&M ISS to investigate what determines the reason why users' switch mobile platforms. Therefore, to test how strongly the direct variables affect usage intention, we included the users' experience in the UTAUT model as a moderating variable.

The flexible universal characteristics [30] of the UTAUT model make it appropriate for the aim of this research, in which we integrated some of the technology acceptance theories and TAM models into a comprehensive model.

\subsection{DeLone and McLean's ISS}

In this study, the D\&M ISS model was applied to recognize the influencing effect of satisfaction and performance expectancy in mobile payment systems on usage intention. D\&M ISS was integrated into UTAUT to measure the information system [31]. System quality (SYQ), service quality (SQ), and information quality (IQ) jointly influence user satisfaction and performance expectancy, both of which eventually affect usage intention.

Since its reinvention, ISS has been broadly applied to evaluate usage willingness in diverse information systems. Mohammadi [32] integrated D\&M ISS into TAM for assessing the influential effect of quality facilitators, performance expectancy, and user satisfaction, as well as the usability in e-learning. Sharma [33] exploited D\&M to survey and measure mobile payment user intention, and proposed a modified conceptual model by expanding D\&M ISS to grasp the actual mobile payment usage intention.

As these studies have demonstrated, even if D\&M ISS has been widely applied to determine customer behavior usage intention, researchers have rarely examined the area of mobile payments among Chinese and Korean customers, which represents advanced payment technology. Hence, the D\&M ISS model should be exploited as a conceptual model of mobile payments [15].

\subsection{TTF}

TTF determines the adaptation between technical abilities and mission requirements; indicating the degree to which technical capabilities are enough to support the task. The theory purports that the adaption between technology functionality and mission requirements affects usage intention (UI) and performance expectancy (PE) [34]. Better adaptation to a mission's technical features will encourage the UI of mobile technology, but worse adaptation decreases the UI [35]. TTF theory supposes consumers are so intelligent that they will continue to use the functions of a specific technology if it supports the mission requirements very well. The customers' acceptance of this model stems from the assumption that the TTF model is a complex model containing three critical models [36]. 
Various fields have adopted the TTF model for determining or predicting the usage intention of mobile payment technologies, e.g., wireless technology [37], mobile banking acceptance [38], mobile commerce [39], and the mobile health [40].

\subsection{Integrating UTAUT and DEM ISS}

Studies have revealed that DeLone and McLean's ISS can be moderately applied in combination with added models. The various treatments of D\&M ISS, in combination with different theories, provided the foundation for our research in relation to m-payments. For instance, individual performance expectancy is an essential issue for user satisfaction in an organizational environment [41]. Individual performance appraisal was found to be a critical factor affecting user satisfaction [42].

In this study, we concentrated on each of the corresponding characteristics of SYQ, SQ, and IQ, such as information system features, information reliability of the mobile payment platform, entire support connected with the service, and their capability to impact and affect PE and satisfaction. The feasibility of sustainably estimating the combination of these three qualities could reduce the corresponding risks of the m-payment service.

We acknowledge the significance of leveraging user satisfaction that associates PE with Korean mobile technology UI: PE supports efficiency and sustainability initiatives of executing m-payment tasks (less time and effort cost) and user satisfaction intermediates between the three qualities and the sustainable use of the technology. A higher correlation between these three factors could reduce the depleting consequences or even enhance the figure of potential consumers. The adopted literature significantly affects and improves the usage intention and adoption of PE.

\subsection{Integrating UTAUT and TTF}

Several surveys indicated that UTAUT could be integrated with some other models, like TTF, to expose mobile payment UI [8]. For example, TAM demonstrated the usage willingness of using cellular technology [43]. Combined with ITM, UTAUT explained mobile banking acceptance [38]. Combined with the TTF model, UTAUT showed how UTAUT mediates between TTF and UI [9].

The authors of the above studies all found that the combination of TTF and UTAUT provided a complete description of the adoption intention compared with the TTF model alone. However, academics still rarely integrated the above structures into a model. Even if some other studies occasionally illustrated the characteristics of mobile payment technology, they failed to propose an integrated model for mobile payment transaction by connecting user satisfaction and performance expectancy through structural equation models with the related research literature to improve the usage intention [36].

UTAUT is a renowned theory only considering the acceptance of information technology (IT), and does not capture the essence of the interest in information technology; TTF adopts a directly objective procedure by supposing that consumers use IT that offers benefits, but does not consider consumers' beliefs in and intents toward IT. The imperfections of the two models were mitigated by integrating them in this study. For example, the limitations of UTAUT are its lack of thought about the characteristics of the task, and how the technical features meet the needs of the m-payment task. Although TTF includes the components of the task and technology, it does not include consumer PE toward the technology, which is the immediate determinant of UI in the core construct of UTAUT.

Therefore, we empirically tested the UTAUT and TTF integrated model, which offered more explanatory power using the SEM method. Appendix A summarized operational definitions of each construct. The analytical report justifies that a combined model results in stronger descriptive evidence than either of the individual models. Several practical results and influences were also considered.

\section{Research Model}

About the proposed model of this research, D\&M ISS and TTF were hypothesized to be the necessary supplementary parts to UTAUT (as shown in Figure 1). Furthermore, task-technology fit, 
user satisfaction as well as performance expectancy and effort expectancy, social influence as well as facilitating conditions were all hypothesized to be determining factors to usage intention. Finally, the differences between the Chinese consumers and Korean consumers were supposed to moderate these determining factors' influence to usage intention.

Given the m-payment background, because consumers do not directly visit the mobile payment organization, system quality has become an "online store" to promote the usage intention of equipment [15]. System quality reflects the convenience, reaction time, reliability, and stability of the user interface [44-46]. The SYQ of m-payment is treated as the ability of the technology to support consumers when completing the payment task. Poor system quality may reduce user satisfaction, because it adds to the difficulty of using m-payments and will not fulfil users' m-payment business needs [42]. Hence:

Hypothesis 1a (H1a). System quality positively affects user satisfaction.

Hypothesis $\mathbf{1 b} \mathbf{( H 1 b ) . ~ S y s t e m ~ q u a l i t y ~ p o s i t i v e l y ~ a f f e c t s ~ p e r f o r m a n c e ~ e x p e c t a n c y . ~}$

DeLone and McLean [31] identified most characteristics of information quality, such as integrality, timeliness, pertinence, and accuracy, which are the essential factors of user satisfaction [7]. Information quality (IQ) includes certain features, such as correlation [46], adequacy [44], and precision [47], which reveal that IQ is one of the critical factors determining user attitude toward technology [48] that they have used.

Information quality includes the expected features of the system (e.g., relevance, accuracy, instantaneity, integrity, comprehension, and accessibility), or even feedback reports [49]. Information quality affects people's behavioral beliefs; for example, perceived convenience eventually affects mobile payment's behavioral attitudes and UI [9]. Therefore, IQ should be regarded as the core structure influencing user satisfaction and performance expectancy [33]. Hence:

Hypothesis 2a (H2a). Information quality positively affects user satisfaction.

Hypothesis $\mathbf{2 b} \mathbf{( H 2 b ) . ~ I n f o r m a t i o n ~ q u a l i t y ~ p o s i t i v e l y ~ a f f e c t s ~ p e r f o r m a n c e ~ e x p e c t a n c y . ~}$

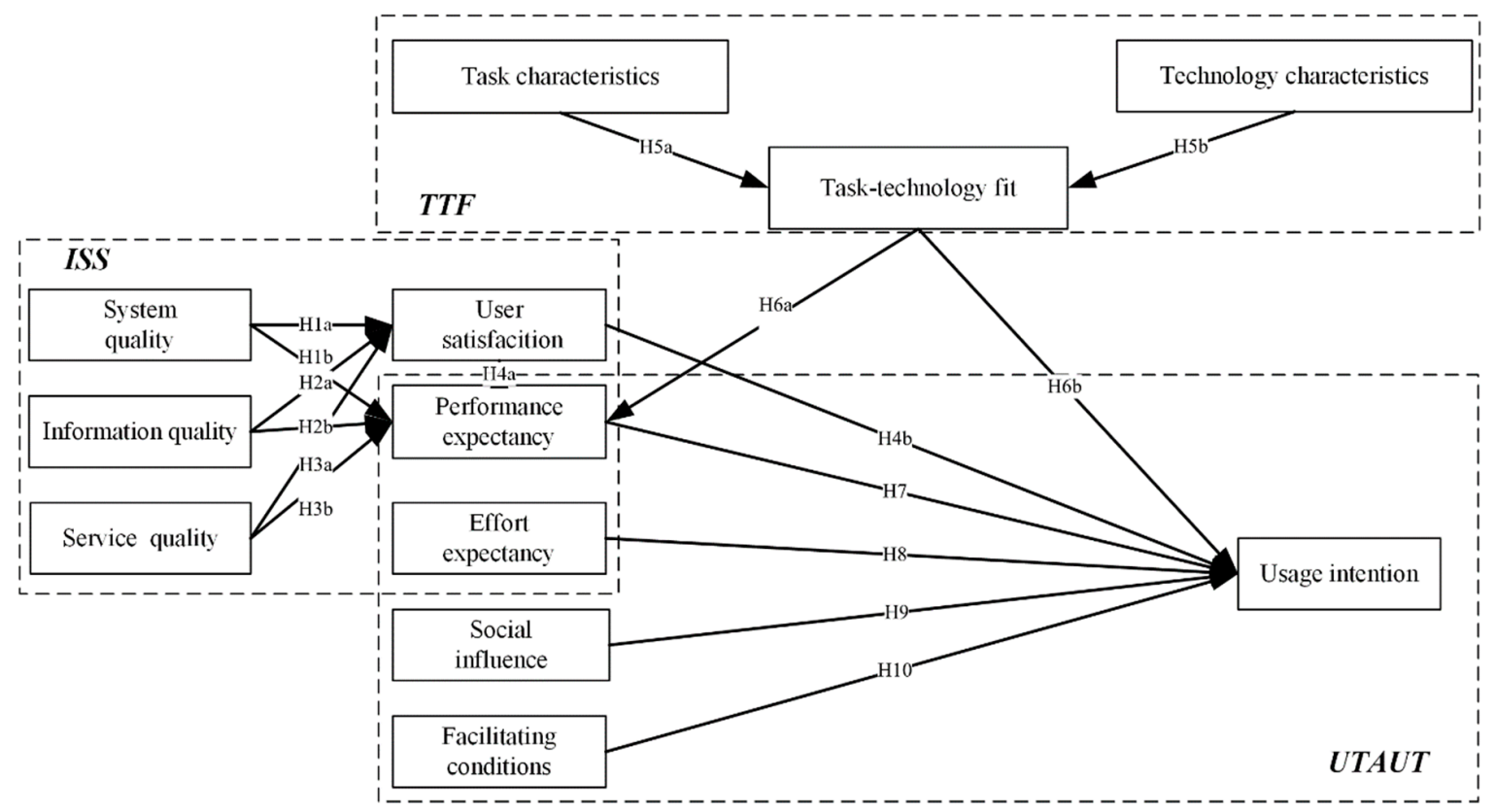

Figure 1. Research model. 
Service quality (SQ) means the characteristics of the service support (e.g., reaction, trustworthiness, brevity, and technological capability) that consumers obtain from the information system department and after-sales service personnel [50]. SQ is commonly defined as how the payment service complements user requirements. Most information system measures emphasize goods quality rather than the service quality, and information system effectiveness cannot be evaluated correctly unless service quality is involved. We think that confirming all the qualities of the support will reduce usage risks. Therefore, the following hypotheses were proposed:

Hypothesis 3a (H3a). Service quality positively affects user satisfaction.

Hypothesis $3 \mathbf{b} \mathbf{( H 3 b )}$. Service quality positively affects performance expectancy.

Performance expectation (PE) in this research is positively correlated with the related model recommended by DeLone and McLean [31], who stated that ISS affects satisfaction and usage intention. According to the revised edition of the ISS model [31], UTAUT explicates that strengthened user satisfaction (US) more significantly influences usage intention, which is subsequently affected by PE. Perceived expectations from D\&M ISS usage reveal the close link between satisfaction and usage willingness [51]. An increase in PE will improve user satisfaction and eventually affect usage willingness. Therefore, the following hypotheses were formed:

Hypothesis 4a (H4a). Performance expectancy positively affects user satisfaction.

Hypothesis $\mathbf{4 b} \mathbf{b} \mathbf{H} 4 \mathbf{b})$. User satisfaction positively affects usage intention.

From a broad TTF perspective, task characteristics (TAC) denote a user's behavior of converting the input into an output to meet their information needs [34]. Tasks can vary in many aspects: Task unconventionality, task relevance, and critical time. The conclusion is that users' usage intention of IT will be lower if tasks need more time cost or information technology provides fewer functions [9]. In the mobile context, the degree of fit between the task characteristics and the technical features determines the extent of TTF [52]. Appropriate task characteristics positively influence users' willingness to use mobile payment technology. In contrast, a weak task feature fitness decreases the consumer's usage willingness $[8,53,54]$. Therefore, the following hypothesis was formulated:

Hypothesis 5a (H5a). Task characteristics positively affect TTF.

Technical characteristics (TEC) are the terminal systems (mobile devices, applications, and transaction information statistics systems) used when performing payment tasks [34]. TEC attracts consumers by allowing access to transaction payment settlement, timely inquiries about logistics, capital flows, and other financial services [9]. Therefore, incorrect or unintentional technology selections will cause one technology to be ignored or masked. Consequently, the following hypothesis is postulated:

Hypothesis $\mathbf{5 b} \mathbf{b} \mathbf{H} \mathbf{b})$. Technology characteristics positively affect TTF.

UTAUT assumes that consumer willingness regarding TTF results in performance expectancy (PE) [9]. The technical characteristics of m-payment will affect effort efficiency (EE). The benefits of m-payment, such as omnipresence and immediateness, allow a consumer to be complete a quick payment and reduce the relevant cost. Compared with the complicated time and space limitation interfaces of traditional credit card payment system, m-payment has fewer characteristics and dedicated interfaces. This advantage may reduce the complexity of user operations. Therefore, the TTF factor will influence a consumer's PE [55], and the following hypothesis was formulated:

Hypothesis 6a (H6a). Task-technology fit of m-payment positively affects performance expectancy. 
TTF is a technical perspective of how new technologies optimize work tasks. It is affected by task requirements and the matching degree of technical features. As such, TTF affects the intention of the consumer toward mobile payment [9]. Previous research has experientially confirmed that TTF significantly affects user intention. Therefore, we hypothesized the following:

Hypothesis $\mathbf{6 b}$ (H6b). Task-technology fit positively affects usage intention.

Venkatesh [56] interpreted PE as "how much technology will benefit consumers to accomplish certain tasks". Therefore, performance expectations affect the different characteristics of information systems, which will benefit consumers. For example, Jaradat [57] and Lee [58] reported that performance expectations are essential predictors of willingness to use mobile commerce. Current evidence suggests that PE is essential to the application of m-payment $[9,59,60]$. Therefore, we hypothesized that:

Hypothesis 7 (H7). Performance expectancy positively affects usage intention.

Efforts expectancy (EE) is conceptualized as "the comfort level of consumer adoption technology" [56]. EE approximates the usability structure in TAM-that is, people think that using a given system will be effortless. Given the background of mobile payments, EE can be determined by the ability to finish a particular mobile payment transaction with minimal effort [52]. Therefore, we hypothesized:

\section{Hypothesis 8 (H8). Effort expectancy positively affects usage intention.}

Social impact (SI) is described as "the level of support that consumers have for using the latest technology equipment" [9]. Social impact reveals the social relatives in influencing individual technological acceptance. Individuals tend to consider other people's opinions when deciding whether to accept an unknown technology. If their attitudes are optimistic, users adopt them; conversely, with negative attitudes, users do not adopt. Jaradat [57] and Chuang [61] proved that SI significantly influences the consumers' UI of m-payment solutions. Hence, we hypothesized that:

Hypothesis 9 (H9). Social influence positively affects usage intention.

The facilitation condition (FC) is described as "the total amount of capital and assistance available that consumers can use to implement actions" [56]. This means that the FC can be viewed as the consumer views of environmental obstacles or available resources that increase the accessibility of mobile payment solutions. Because mobile Internet must be used for mobile payment transactions, it has a significant impact on mobile payment [52]. For example, the convenience or high threshold of specific online service areas can promote or hinder consumers from using mobile payments. From the concept of FC, the convenience conditions affecting the use of the mobile Internet are discussed. Vongjaturapat [62] and Fianu [63] disclosed that FC notably influences usage intention. Therefore, the following hypothesis was formed:

Hypothesis 10 (H10). Facilitating conditions positively affect usage intention.

Im [64] revealed the relationships between the UTAUT variables to determine the moderating effect of nationality. Through an evaluation of U.S. and Korea data, Im reported that the effects of EE on use behavior were greater in the sample of U.S. consumers. Zhang [65] studied an adoption model of mobile commerce, which expanded TAM to the theory of planned behavior (TPB) and IT. Through an adjusted analysis and segmentation test, the context was divided into sub-groups of eastern and western cultures to confirm the adoption of mobile commerce by different national cultures. The results showed that UTAUT perfectly matched the data. Lee et al. [58] revealed the moderating effect of the government's role on the determinants of usage intention in the UTAUT model. 
According to this literature, we statistically tested the moderating effect of the different nationalities of consumers in the UTAUT model. We assumed that some differences exist in the national role that moderates these determinants' influence on UI. Therefore, the following hypotheses were tested:

Hypothesis 11 (H11). The impact of facilitating conditions on usage intention differs between Chinese and Korean consumers.

Hypothesis 12 (H12). The effect of social influence on usage intention differs between Chinese and Korean consumers.

Hypothesis 13 (H13). The influence of effort expectancy on usage intention differs between Chinese and Korean consumers.

Hypothesis 14 (H11). The influence of performance expectancy on usage intention differs between Chinese and Korean consumers.

Hypothesis 15 (H15). The impact of satisfaction on usage intention differs between Chinese and Korean consumers.

Hypothesis 16 (H16). The impact of task-technology fit on usage intention differs between Chinese and Korean consumers.

\section{Data Collection and Results}

On 21 February 2017, China Ant Financial of Alibaba Co., Ltd. invested \$200 million USD in Kakaopay, which was launched separately to manage the payment transactions operated by the company two months later. This means that in the foreseeable future, Kakaopay will be able to provide joint services support with Alipay to service 450 million Chinese and Korean consumers' m-payment requirements. Due to the increasing number of Chinese consumers, Korean mobile payment providers should explore the Chinese user market [6].

As a comprehensive financial platform with a considerable scale in the Asia-Pacific region, Kakaopay has the following sustainability characteristics: Higher electricity supplier penetration, financial support and financial transactions integrated with cryptocurrencies like bitcoin and Ethereum, and joint services support with Alipay, which will provide 450 million Chinese and Korean consumers in the foreseeable future [6].

This research designed questionnaires based on the above assumptions. In the pre-test, all variables and related measurement items were extended to follow the theme and background of this research, referring to the relevant literature. After the questionnaire design was completed, nearly 100 participants who often conducted transactions using Kakaopay were invited to complete a pre-test via face-to-face interviews. The ambiguous or easily misunderstood parts of the questionnaire were then modified so that participants could fully identify the content of the questionnaire, improving the accuracy of the survey. Considering the advantages of online questionnaires, such as their low cost, ability to provide fast feedback, wide-coverage, and lack of a time limitation [66-68], the second group of about 200 participants was recruited from the Kakaopay after-sales information feedback center, who had bought e-ecommerce products using Kakaopay. In the pre-test, each group strictly excluded those who had not used Kakaopay products or services. The remaining data were obtained from the experienced Chinese and Korean users in Seoul from face-to-face interviews, where mobile commerce was more mature than other parts of Korea, so that we could quickly obtain enough samples. In Seoul, we randomly intercepted the Chinese and Korean individuals and identified suitable subjects who had used Kakaopay online. The suitable users received the questionnaires and completed them according to their own usage intention. Every individual who completed the survey received a gift reward.

According to the procedure proposed by Armstrong et al. [69], we found no significant difference in the Chi-square test results at the 5\% significance level between participants who answered the 
questionnaire via a face-to-face interview and those who answered online from the perspective of age, education, and occupation.

This study gathered relative statistical data to target both the Chinese who were foreign residents in Korea for over 10 weeks and the Korean population. To achieve an adequate response rate, surveys were sent using both online and blended delivery methods. Altogether 1300 questionnaires were issued, 1124 responses were collected (response rate of $86.46 \%$ ). After discarding 216 responses, due to missing data or the lack of Kakaopay usage experience, a sample of $908(80.78 \%)$ was eventually used in the decisive analysis (467 Chinese data and 441 Korean data). These data were enough to determine the dissimilarities between the two target populations, even with different sample numbers. A 5-point Likert scale was used for all questions ranging from 1, "strongly refuse", to 5, "strongly approve".

In the following empirical analysis, Cronbach's $\alpha$ was used via IBM SPSS 24.0 to calculate the measuring means' reliability and to test each construct and evaluate the construct validity by examining the factor structure and internal correlations. To test the research hypotheses, we used IBM AMOS 24.0, which also confirmed the causality between the endogenous core variables via standard coefficients and significance values. Before the hypothetical verification test, the integrated model was analyzed using the entire sample. For hypothetical verification, we conducted more specific analyses with the model applied to the groups.

We addressed the experience of Chinese and Korean customers in Korea, including travelers, professional staff, and part-time working students in Korea. Since middle-aged customers and women represent the largest group using the mobile payment system, a total of 590 respondents $(60 \%)$ were female, and $707(77.86 \%)$ of the suitable interviewees were around 40 years old. Table 1 provides detailed statistical results relating to the respondents' characteristics.

Table 1. Sample characteristics (entire samples).

\begin{tabular}{|c|c|c|c|c|c|}
\hline & \multirow{2}{*}{ Variable } & \multicolumn{2}{|c|}{ Chinese } & \multicolumn{2}{|c|}{ Korean } \\
\hline & & Number & Percentage & Number & Percentage \\
\hline \multirow[b]{2}{*}{ Sex } & Male & 161 & $34.5 \%$ & 157 & $35.6 \%$ \\
\hline & Female & 306 & $65.5 \%$ & 284 & $64.4 \%$ \\
\hline \multirow{5}{*}{ Age (years) } & Below 20 & 52 & $11.1 \%$ & 38 & $8.6 \%$ \\
\hline & $20-30$ & 34 & $7.3 \%$ & 27 & $6.1 \%$ \\
\hline & $30-40$ & 186 & $39.8 \%$ & 171 & $38.8 \%$ \\
\hline & $40-50$ & 165 & $35.3 \%$ & 185 & $42.0 \%$ \\
\hline & Over 50 & 30 & $6.4 \%$ & 20 & $4.5 \%$ \\
\hline \multirow{3}{*}{ Education } & $\begin{array}{c}\text { High school } \\
\text { student/resident }\end{array}$ & 47 & $10.1 \%$ & 42 & $9.5 \%$ \\
\hline & College student/student & 200 & $42.8 \%$ & 197 & $44.7 \%$ \\
\hline & Graduate school or higher & 220 & $47.1 \%$ & 202 & $45.8 \%$ \\
\hline \multirow{5}{*}{ Occupation } & Professional & 44 & $9.4 \%$ & 40 & $9.1 \%$ \\
\hline & Self-employed & 156 & $33.4 \%$ & 172 & $39.0 \%$ \\
\hline & Office worker & 160 & $34.3 \%$ & 129 & $29.3 \%$ \\
\hline & Student & 87 & $18.6 \%$ & 89 & $20.2 \%$ \\
\hline & Other & 20 & $4.3 \%$ & 11 & $2.5 \%$ \\
\hline Experience & Yes & 467 & $100.0 \%$ & 441 & $100.0 \%$ \\
\hline
\end{tabular}

\subsection{Reliability and Validity}

Three steps are necessary when evaluating the convergent effectiveness of the measurement objects to their related constructs. Firstly, standardized loadings are applied to evaluate every index's reliability. Secondly, Cronbach's $\alpha$ and the composite reliability (CR) value of each construct is used to measure the overall CR. As an empirical analysis measure, Cronbach's $\alpha$ is used to evaluate the composite materials' reliability. CR is calculated using the index load and its error variances. Thirdly, 
the average variance extracted (AVE) evaluates the variance acquired by the variables relative to the variance owing to a measurement error [70].

Table 2 displays the results of the reliability and validity analysis, indicating that the variables meet all the criteria. Supported by Table 2, the standardized loadings of the single project surpassed the minimum amount of 0.50; Cronbach's $\alpha$ and the CR value were higher than 0.70, and the AVE of each structure was higher than 0.50 , which indicated the ideal validity of the measurement interpretation structure and the higher level of composite reliability [70-72]. The Cronbach's $\alpha$ analysis results demonstrated the high internal consistency between the variables, and the other obtained results supported sufficient reliability and validity of internal consistency.

Table 2. Standardized loading, reliability, and effectiveness measures of variables (entire samples). AVE, average variance extracted.

\begin{tabular}{|c|c|c|c|c|c|}
\hline Construct & Indicators & $\begin{array}{l}\text { Standardized } \\
\text { Loading } \\
(t \text {-Value })\end{array}$ & $\begin{array}{c}\text { Cronbach's } \\
\alpha\end{array}$ & $\begin{array}{l}\text { Composite } \\
\text { Reliability }\end{array}$ & AVE \\
\hline \multirow{4}{*}{ System quality (SYQ) } & SYQ1 & 0.849 & 0.827 & 0.834 & 0.559 \\
\hline & SYQ2 & 0.754 & - & - & - \\
\hline & SYQ3 & 0.685 & - & - & - \\
\hline & SYQ4 & 0.690 & - & - & - \\
\hline \multirow{4}{*}{ Information quality (IQ) } & IQ1 & 0.834 & 0.912 & 0.913 & 0.726 \\
\hline & IQ2 & 0.915 & - & - & - \\
\hline & IQ3 & 0.836 & - & - & - \\
\hline & IQ4 & 0.819 & - & - & - \\
\hline \multirow{4}{*}{ Service quality (SQ) } & SQ1 & 0.764 & 0.860 & 0.860 & 0.607 \\
\hline & SQ2 & 0.768 & - & - & - \\
\hline & SQ3 & 0.799 & - & - & - \\
\hline & SQ4 & 0.784 & - & - & - \\
\hline \multirow{4}{*}{ User satisfaction (US) } & US1 & 0.761 & 0.870 & 0.874 & 0.635 \\
\hline & US2 & 0.859 & - & - & - \\
\hline & US3 & 0.779 & - & - & - \\
\hline & US4 & 0.778 & - & - & - \\
\hline \multirow{4}{*}{ Performance expectancy (PE) } & PE1 & 0.762 & 0.860 & 0.873 & 0.632 \\
\hline & PE2 & 0.765 & - & - & - \\
\hline & PE3 & 0.860 & - & - & - \\
\hline & PE4 & 0.742 & - & - & - \\
\hline \multirow{4}{*}{ Effort expectancy (EE) } & EE1 & 0.786 & 0.828 & 0.833 & 0.559 \\
\hline & EE2 & 0.609 & - & - & - \\
\hline & EE3 & 0.820 & - & - & - \\
\hline & EE4 & 0.757 & - & - & - \\
\hline \multirow{4}{*}{ Social influence (SI) } & SI1 & 0.647 & 0.833 & 0.841 & 0.571 \\
\hline & SI2 & 0.873 & - & - & - \\
\hline & SI3 & 0.724 & - & - & - \\
\hline & SI 4 & 0.762 & - & - & - \\
\hline \multirow{4}{*}{ Facilitating conditions (FC) } & FC1 & 0.838 & 0.815 & 0.820 & 0.535 \\
\hline & FC2 & 0.637 & - & - & - \\
\hline & FC3 & 0.767 & - & - & - \\
\hline & FC4 & 0.667 & - & - & - \\
\hline \multirow{4}{*}{ Task characteristics (TAC) } & TAC1 & 0.872 & 0.843 & 0.846 & 0.582 \\
\hline & TAC2 & 0.753 & - & - & - \\
\hline & TAC3 & 0.656 & - & - & - \\
\hline & TAC4 & 0.754 & - & - & - \\
\hline
\end{tabular}


Table 2. Cont.

\begin{tabular}{|c|c|c|c|c|c|}
\hline Construct & Indicators & $\begin{array}{c}\text { Standardized } \\
\text { Loading } \\
(t \text {-Value })\end{array}$ & $\begin{array}{c}\text { Cronbach's } \\
\alpha\end{array}$ & $\begin{array}{l}\text { Composite } \\
\text { Reliability }\end{array}$ & AVE \\
\hline \multirow{4}{*}{$\begin{array}{l}\text { Technology characteristics } \\
\text { (TEC) }\end{array}$} & TEC1 & 0.794 & 0.854 & 0.855 & 0.596 \\
\hline & TEC2 & 0.795 & - & - & - \\
\hline & TEC3 & 0.757 & - & - & - \\
\hline & TEC4 & 0.740 & - & - & - \\
\hline \multirow{4}{*}{ Task-technology Fit (TTF) } & TTF1 & 0.815 & 0.887 & 0.898 & 0.687 \\
\hline & TTF2 & 0.799 & - & - & - \\
\hline & TTF3 & 0.836 & - & - & - \\
\hline & TTF4 & 0.865 & - & - & - \\
\hline \multirow{4}{*}{ Usage intention (UI) } & UI1 & 0.765 & 0.894 & 0.896 & 0.684 \\
\hline & UI2 & 0.802 & - & - & - \\
\hline & UI3 & 0.847 & - & - & - \\
\hline & UI4 & 0.890 & - & - & - \\
\hline
\end{tabular}

In Table 3, the discriminant validity shows the degree to which a principle with its related indexes vary from the second principle with the associated indexes [73]. Fornell et al. [72] revealed that the relationship between variables in any two structures must be inferior to the square root of the average variances shared by items of one structure.

Table 3. Discriminant validity (entire sample).

\begin{tabular}{|c|c|c|c|c|c|c|c|c|c|c|c|c|}
\hline & SYQ & IQ & SQ & US & PE & EE & SI & FC & TAC & TEC & TTF & UI \\
\hline SYQ & 0.748 & & & & & & & & & & & \\
\hline IQ & 0.324 & 0.852 & & & & & & & & & & \\
\hline $\mathrm{SQ}$ & 0.363 & 0.298 & 0.779 & & & & & & & & & \\
\hline$\widehat{\mathrm{US}}$ & 0.588 & 0.563 & 0.295 & 0.797 & & & & & & & & \\
\hline PE & 0.581 & 0.502 & 0.339 & 0.664 & 0.795 & & & & & & & \\
\hline $\mathrm{EE}$ & 0.018 & 0.086 & 0.057 & 0.016 & -0.011 & 0.748 & & & & & & \\
\hline SI & 0.294 & 0.195 & 0.267 & 0.230 & 0.192 & -0.005 & 0.756 & & & & & \\
\hline $\mathrm{FC}$ & 0.323 & 0.302 & 0.272 & 0.234 & 0.290 & 0.042 & 0.270 & 0.731 & & & & \\
\hline TAC & 0.335 & 0.225 & 0.244 & 0.274 & 0.340 & 0.070 & 0.263 & 0.310 & 0.763 & & & \\
\hline TEC & 0.325 & 0.262 & 0.314 & 0.231 & 0.359 & 0.071 & 0.293 & 0.235 & 0.229 & 0.772 & & \\
\hline TTF & 0.283 & 0.211 & 0.252 & 0.263 & 0.555 & 0.026 & 0.233 & 0.234 & 0.557 & 0.614 & 0.829 & \\
\hline UI & 0.352 & 0.367 & 0.276 & 0.516 & 0.569 & 0.064 & 0.554 & 0.455 & 0.377 & 0.370 & 0.514 & 0.827 \\
\hline
\end{tabular}

Table 3 shows that compared with the correlations among the structures and other structures, the square root of the variance among structures with their terms was larger, which met every criteria of discriminant validity [72]. The diagonal values surpassing the correlation between constructs proved that our measurement tool had satisfactory construct validity.

\subsection{Measurement Model Evaluation}

In evaluating the collected data, we adopted the two-process procedure proposed by Anderson et al. [74]. Firstly, the convergent and discriminant validity was tested. Secondly, the measurement model used to investigate the theoretical constructs' relationships was assessed.

Before the Chinese and Korean consumers' data were separately analyzed, the integrated model was examined using the entire dataset. To test the fitting of measurements and structural modeling, Hooper et al. [75] proposed model fit as an absolute fit index, and recommended the following indices (Table 4) as incremental fit indices. 
Table 4. Fit indicators of the measurement and structural models (entire samples).

\begin{tabular}{ccccc}
\hline Fit Index & Standard of Fit Index & $\begin{array}{c}\text { Measurement } \\
\text { Model }\end{array}$ & $\begin{array}{c}\text { Structural } \\
\text { Model }\end{array}$ & Result \\
\hline$\chi^{2} /$ d.f. & $\leq 3.00$ & 1.248 & 1.302 & Yes \\
GFI & $>0.90$ & 0.946 & 0.943 & Yes \\
AGFI & $>0.90$ & 0.937 & 0.935 & Yes \\
NFI & $>0.90$ & 0.949 & 0.945 & Yes \\
CFI & $>0.90$ & 0.989 & 0.987 & Yes \\
IFI & $>0.90$ & 0.989 & 0.987 & Yes \\
RFI & $>0.90$ & 0.943 & 0.941 & Yes \\
PGFI & $>0.50$ & 0.816 & 0.831 & Yes \\
PCFI & $>0.50$ & 0.889 & 0.906 & Yes \\
PNFI & $>0.50$ & 0.853 & 0.868 & Yes \\
RMR & $<0.08$ & 0.033 & 0.038 & Yes \\
RMSEA & $<0.08$ & 0.017 & 0.018 & Yes \\
\hline
\end{tabular}

Notes: $\chi^{2} /$ d.f. chi-squared divided by degrees of freedom; GFI, goodness-of-fit index; AGFI, adjusted goodness-of-fit index; NFI, normed fit index; CFI, comparative fit index; IFI, incremental fit index; RFI, relative fit index; PGFI, parsimony goodness-of-fit index; PCFI, parsimonious comparative fit index; PNFI, parsimonious normed fit index; RMR, root mean square residual; RMSEA, root mean square error of approximation.

The SEM was applied to test the 16 hypotheses proposed in this research. For the parsimonious fit indices herein all exceeded the acceptable fitness minimum values which were a relatively strict standard of recommended values. As shown in Table 4, all fit indices indicate a satisfactory model match between the analytical data and the composite model.

\subsection{Hypothesis Verification}

After confirming the suitability of the measurement and structure of the integrated model, the model was analyzed with the Chinese sample, and the Chinese path coefficients were assessed, as shown in Figure 2. According to the p-values, 4 of the 16 paths (H3a, H3b, H6b, and H8) were rejected, but the other 12 paths had statistically significant characteristics.

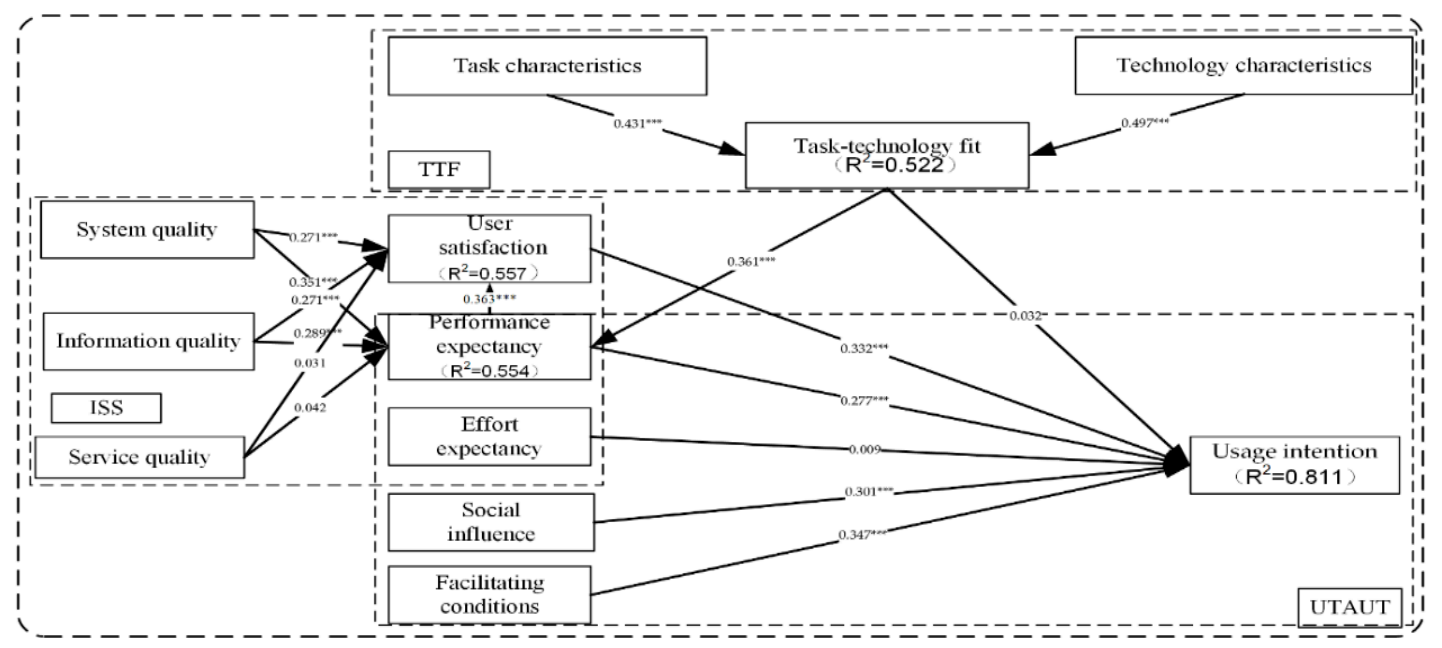

Figure 2. Path analysis of the research model (Chinese experience consumers). $R^{2}$ is the coefficient of determination.

The UI of the Chinese consumers was indicated by TTF ( $\beta=0.032)$, US ( $\beta=0.332)$, PE $(\beta=0.277)$, EE ( $\beta=0.009)$, SI $(\beta=0.301)$, and FC $(\beta=0.347)$, which jointly explained $81.1 \%$ of the variance in UI.

The impact on Chinese consumers (Figure 2 ) showed that the antecedents of TTF, ISS, and UTAUT models respectively explained $52.2 \%, 55.7 \%$, and $55.4 \%$ of the variances, all of which were to the $81.1 \%$ explanatory power of the integrated model towards usage intention. 
Given the satisfactory measurement and structure result, the integrated model was analyzed with the Korean sample. Figure 3 shows that the Korean path coefficients of the integrated model among the fundamental hypotheses were appropriately assessed. According to the respective p-values, 6 of the 16 paths (H3a, H3b, H4b, H7, H8, and H10) were rejected, but the other paths had statistically significant characteristics.

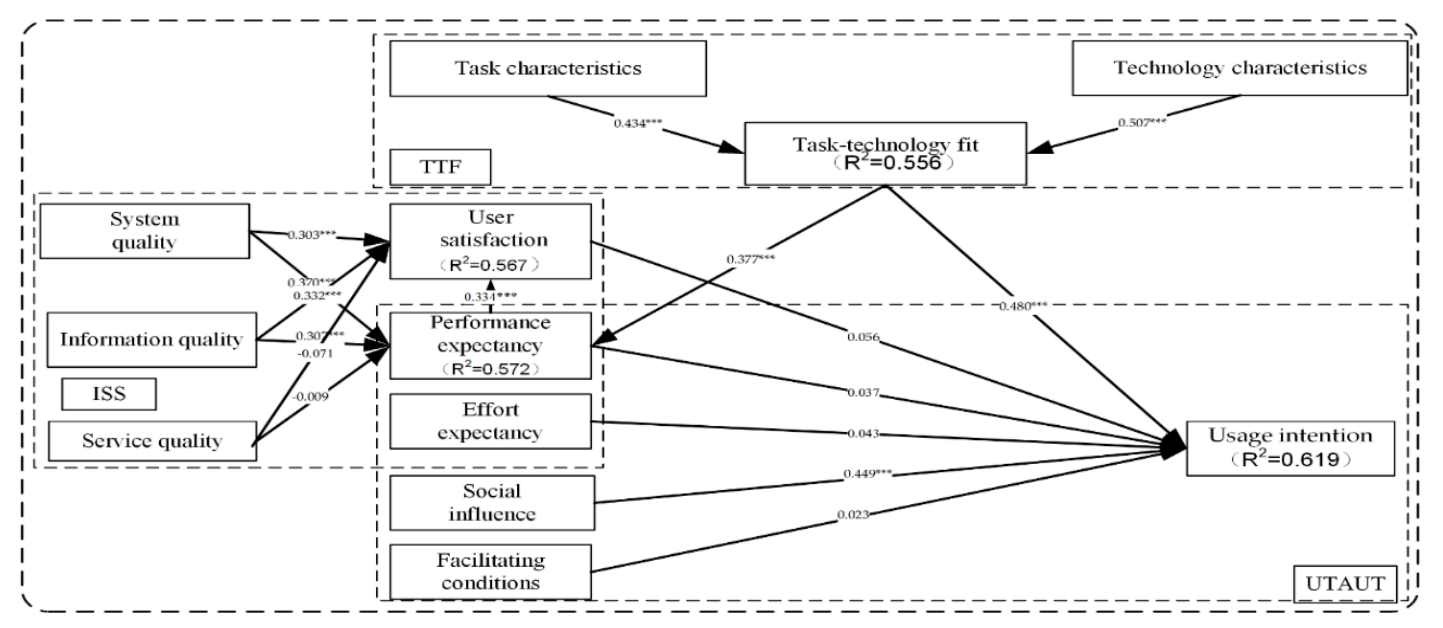

Figure 3. Path analysis of the research model (Korean experience consumers).

UI of the Korean consumers was predicted by TTF $(\beta=0.480)$, US ( $\beta=0.056)$, PE $(\beta=0.037)$, EE ( $\beta=0.043)$, SI $(\beta=0.449)$, and FC $(\beta=0.023)$, which jointly explained $61.9 \%$ of the variance in Korean consumers' usage intention. The impact on Korean consumers (Figure 3) showed that the antecedents of TTF, ISS, and UTAUT models respectively explained $55.6 \%, 56.7 \%$, and $57.2 \%$ of the variances, all of which were to the $61.9 \%$ explanatory power of the integrated model towards usage intention.

The empirical analysis results of the entire samples in Table 5 show that three paths (H3a, H3b, and H8; $p$-values $>0.05$ ) were not supported, whereas the remaining paths were significant at 0.05 . The characteristics of the causal paths are listed in Table 5 , including the path coefficients and hypothesis test results of the hypothetical model. Table 5 proves that the series of statistics results support the integrated model.

Table 5. Results of hypotheses tests (all samples).

\begin{tabular}{|c|c|c|c|c|}
\hline Hypothesis & Path & Path Coefficients & $p$-Value & T-Value \\
\hline H1a & System quality $\rightarrow$ User satisfaction & 0.293 & $* * *$ & 7.462 \\
\hline $\mathrm{H} 1 \mathrm{~b}$ & System quality $\rightarrow$ Performance expectancy & 0.363 & $* * *$ & 10.21 \\
\hline $\mathrm{H} 2 \mathrm{a}$ & Information quality $\rightarrow$ User satisfaction & 0.300 & $* * *$ & 8.71 \\
\hline $\mathrm{H} 2 \mathrm{~b}$ & Information quality $\rightarrow$ Performance expectancy & 0.296 & $* * *$ & 9.314 \\
\hline $\mathrm{H} 3 \mathrm{a}$ & Service quality $\rightarrow$ User satisfaction & -0.022 & 0.492 & -0.687 \\
\hline $\mathrm{H} 3 \mathrm{~b}$ & Service quality $\rightarrow$ Performance expectancy & 0.018 & 0.574 & 0.562 \\
\hline $\mathrm{H} 4 \mathrm{a}$ & Performance expectancy $\rightarrow$ User satisfaction & 0.347 & $* * *$ & 8.159 \\
\hline $\mathrm{H} 4 \mathrm{~b}$ & User satisfaction $\rightarrow$ Usage Intention & 0.199 & $* * *$ & 5.081 \\
\hline $\mathrm{H} 5 \mathrm{a}$ & Task characteristics $\rightarrow$ Task-Technology Fit & 0.433 & $* * *$ & 13.388 \\
\hline $\mathrm{H} 5 \mathrm{~b}$ & Tech characteristics $\rightarrow$ Task-Technology Fit & 0.504 & $* * *$ & 14.564 \\
\hline H6a & Task-Technology Fit $\rightarrow$ Performance expectancy & 0.370 & $* * *$ & 11.378 \\
\hline $\mathrm{H} 6 \mathrm{~b}$ & Task-Technology Fit $\rightarrow$ Usage Intention & 0.225 & $* * *$ & 6.687 \\
\hline $\mathrm{H} 7$ & Performance expectancy $\rightarrow$ Usage Intention & 0.173 & $* * *$ & 3.812 \\
\hline $\mathrm{H} 8$ & Effort expectancy $\rightarrow$ Usage Intention & 0.047 & 0.077 & 1.77 \\
\hline H9 & Social influence $\rightarrow$ Usage Intention & 0.358 & $* * *$ & 10.874 \\
\hline $\mathrm{H} 10$ & Facilitating conditions $\rightarrow$ Usage Intention & 0.196 & $* * *$ & 6.526 \\
\hline
\end{tabular}


The integrated model was also analyzed with the Chinese sample, as shown in Table 6. The empirical analysis results of the Chinese sample in Table 6 show that the integrated model is supported. Based on the Chinese sample, four paths (H3a, H3b, H6b, and H8; $p$-values > 0.05) were not supported, whereas the remaining paths were significant at the 0.05 level. The characteristics of the causal paths, the standardized path coefficients, and hypothesis test results of the hypothetical model are listed in Table 6. The integrated model was analyzed with the Korean sample, as shown in Table 7.

Table 6. Results of hypotheses tests (Chinese consumers' sample).

\begin{tabular}{|c|c|c|c|c|}
\hline Hypothesis & Path & Path Coefficients & $p$-Value & T-Value \\
\hline $\mathrm{H} 1 \mathrm{a}$ & System quality $\rightarrow$ User satisfaction & 0.271 & $* * *$ & 4.963 \\
\hline $\mathrm{H} 1 \mathrm{~b}$ & System quality $\rightarrow$ Performance expectancy & 0.351 & $* * *$ & 7.038 \\
\hline $\mathrm{H} 2 \mathrm{a}$ & Information quality $\rightarrow$ User satisfaction & 0.271 & $* * *$ & 5.781 \\
\hline $\mathrm{H} 2 \mathrm{~b}$ & Information quality $\rightarrow$ Performance expectancy & 0.289 & $* * *$ & 6.648 \\
\hline $\mathrm{H} 3 \mathrm{a}$ & Service quality $\rightarrow$ User satisfaction & 0.031 & 0.491 & 0.688 \\
\hline $\mathrm{H} 3 \mathrm{~b}$ & Service quality $\rightarrow$ Performance expectancy & 0.042 & 0.355 & 0.925 \\
\hline $\mathrm{H} 4 \mathrm{a}$ & Performance expectancy $\rightarrow$ User satisfaction & 0.363 & $* * *$ & 6.208 \\
\hline $\mathrm{H} 4 \mathrm{~b}$ & User satisfaction $\rightarrow$ Usage Intention & 0.332 & $* * *$ & 7.142 \\
\hline $\mathrm{H} 5 \mathrm{a}$ & Task characteristics $\rightarrow$ Task-Technology Fit & 0.431 & $* * *$ & 9.456 \\
\hline $\mathrm{H} 5 \mathrm{~b}$ & Tech characteristics $\rightarrow$ Task-Technology Fit & 0.497 & $* * *$ & 10.395 \\
\hline H6a & Task-Technology Fit $\rightarrow$ Performance expectancy & 0.361 & $* * *$ & 8.077 \\
\hline $\mathrm{H} 6 \mathrm{~b}$ & Task-Technology Fit $\rightarrow$ Usage Intention & 0.032 & 0.378 & 0.881 \\
\hline $\mathrm{H} 7$ & Performance expectancy $\rightarrow$ Usage Intention & 0.277 & $* * *$ & 5.304 \\
\hline $\mathrm{H} 8$ & Effort expectancy $\rightarrow$ Usage Intention & 0.009 & 0.767 & 0.296 \\
\hline H9 & Social influence $\rightarrow$ Usage Intention & 0.301 & $* * *$ & 8.098 \\
\hline $\mathrm{H} 10$ & Facilitating conditions $\rightarrow$ Usage Intention & 0.347 & $* * *$ & 9.069 \\
\hline
\end{tabular}

$$
\text { Note: }{ }^{*} p<0.05 ;{ }^{* *} p<0.01 ;{ }^{* * *} p<0.001 \text {. }
$$

Table 7. Results of hypotheses tests (Korean consumers' sample).

\begin{tabular}{ccccc}
\hline Hypothesis & Path & Path Coefficients & $p$ & T-Value \\
\hline H1a & System quality $\rightarrow$ User satisfaction & 0.303 & $* * *$ & 5.404 \\
$\mathrm{H} 1 \mathrm{~b}$ & System quality $\rightarrow$ Performance expectancy & 0.370 & $* * *$ & 7.252 \\
$\mathrm{H} 2 \mathrm{a}$ & Information quality $\rightarrow$ User satisfaction & 0.332 & $* * *$ & 6.539 \\
$\mathrm{H} 2 \mathrm{~b}$ & Information quality $\rightarrow$ Performance expectancy & 0.307 & $* .47$ & 6.479 \\
$\mathrm{H} 3 \mathrm{a}$ & Service quality $\rightarrow$ User satisfaction & -0.071 & 0.114 & -1.581 \\
$\mathrm{H} 3 \mathrm{~b}$ & Service quality $\rightarrow$ Performance expectancy & -0.009 & 0.851 & -0.188 \\
$\mathrm{H} 4 \mathrm{a}$ & Performance expectancy $\rightarrow$ User satisfaction & 0.334 & $* * *$ & 5.407 \\
$\mathrm{H} 4 \mathrm{~b}$ & User satisfaction $\rightarrow$ Usage Intention & 0.056 & 0.327 & 0.98 \\
$\mathrm{H} 5 \mathrm{a}$ & Task characteristics $\rightarrow$ Task-Technology Fit & 0.434 & $* * *$ & 9.479 \\
$\mathrm{H} 5 \mathrm{~b}$ & Tech characteristics $\rightarrow$ Task-Technology Fit & 0.507 & $* * *$ & 10.126 \\
$\mathrm{H} 6 \mathrm{a}$ & Task-Technology Fit $\rightarrow$ Performance expectancy & 0.377 & $* * *$ & 7.902 \\
$\mathrm{H} 6 \mathrm{~b}$ & Task-Technology Fit $\rightarrow$ Usage Intention & 0.480 & $* * *$ & 8.524 \\
$\mathrm{H} 7$ & Performance expectancy $\rightarrow$ Usage Intention & 0.037 & 0.587 & 0.543 \\
$\mathrm{H} 8$ & Effort expectancy $\rightarrow$ Usage Intention & 0.043 & 0.265 & 1.114 \\
$\mathrm{H} 9$ & Social influence $\rightarrow$ Usage Intention & 0.449 & $* * *$ & 8.449 \\
$\mathrm{H} 10$ & Facilitating conditions $\rightarrow$ Usage Intention & 0.023 & 0.587 & 0.544 \\
\hline
\end{tabular}

Note: ${ }^{*} p<0.05 ;{ }^{* *} p<0.01 ;{ }^{* * *} p<0.001$.

The characteristics of the causal paths, the standardized path coefficients, and hypothesis test results of the hypothetical model are listed in Table 7. The empirical analysis results of the Korean sample in Table 7 confirm that the integrated model was supported. Based on the Korean sample, five paths (H3a, H3b, H4b, H7, and H8; $p$-values > 0.05 ) were not supported, whereas the remaining paths were significant at the 0.05 level. 


\subsection{Analysis of the Differences in Path Coefficients Between Chinese and Korean Groups}

This research paid more attention to the differences between Chinese and Korean consumer income groups in terms of the mobile payment UI. Comparing these two consumer groups had two advantages. Firstly, in terms of the gaps in income level, purchasing power, and network quality, the Chinese and Korean groups represented two unique and mutually different demographic characteristics. Secondly, Chinese consumers played the most critical role in online shopping. Although Chinese consumers tended to be lower-income consumers and had less experience with Kakaopay than Korean consumers, Chinese mobile payment use patterns were entirely different. Therefore, an evaluation comparing Chinese and Korean customers might improve our understanding of UI [7]. In this research, PE, EE, SI, FC, and TTF were the factors directly determining UI, so we further studied them. The differences in the roles between Chinese and Korean groups are supposed to moderate these factors' influence on UI.

Table 8 shows the empirical research results for the moderating effects of the hypotheses (H11-H16). Firstly, for both $p$-values of SI on UI and EE on UI, the Chinese and Korean groups' moderating effects were insignificant. Secondly, the other four $p$-values revealed the moderating effects' differences between the Chinese and Korean groups. In the Chinese group, the FC $(\beta=0.347, p<0.01), \mathrm{PE}$ ( $\beta=0.277, p<0.01)$, and US ( $\beta=0.332, p<0.01)$ significantly influenced UI at the $5 \%$ significance level, unlike in the Korean group. Conversely, TTF $(\beta=0.480, p<0.01)$ significantly affected UI at the $1 \%$ significance level in the Korean group, unlike in the Chinese group.

Table 8. The difference of path coefficients between Chinese and Korean consumers.

\begin{tabular}{ccccccc}
\hline \multirow{2}{*}{ Route } & \multicolumn{2}{c}{ Chinese } & \multicolumn{2}{c}{ Korean } & \multicolumn{2}{c}{$\begin{array}{c}\text { Pairwise Parameter } \\
\text { Comparisons }\end{array}$} \\
\cline { 2 - 7 } & $\boldsymbol{\beta}$ & $\boldsymbol{p}$ & $\boldsymbol{\beta}$ & $\boldsymbol{p}$ & $\boldsymbol{T}$ Value & $\boldsymbol{p}$-Value \\
\hline $\mathrm{FC} \rightarrow$ UI & 0.347 & $* * *$ & 0.023 & 0.587 & 6.441 & 0.000 \\
$\mathrm{SI} \rightarrow$ UI & 0.301 & $* * *$ & 0.449 & $* * *$ & 1.882 & 0.060 \\
$\mathrm{EE} \rightarrow$ UI & 0.0009 & 0.767 & 0.043 & 0.265 & 0.645 & 0.519 \\
$\mathrm{PE} \rightarrow$ UI & 0.277 & $* * *$ & 0.037 & 0.587 & 2.971 & 0.003 \\
$\mathrm{US} \rightarrow$ UI & 0.332 & $* * *$ & 0.056 & 0.327 & 4.217 & 0.000 \\
$\mathrm{TTF} \rightarrow$ UI & 0.032 & 0.378 & 0.480 & $* * *$ & 6.242 & 0.000 \\
\hline
\end{tabular}

Note: US = user satisfaction; $\mathrm{PE}=$ performance expectancy; UI = usage intention; TTF = task-technology fit; $\mathrm{EE}=$ effort expectancy; $\mathrm{SI}=$ social influence; $\mathrm{FC}=$ facilitating conditions. $p$-values $<0.001$ represent a significant difference between Chinese and Korean groups.

\section{Conclusions}

\subsection{Research Findings}

As the scale of Internet shopping increases rapidly in Korea, the number of foreign mobile payment users is increasing precipitously. However, mobile payment providers cannot attract international customers, especially Chinese customers, without understanding their intention to use mobile payment technology. Hence, an integrated model for mobile payment providers is essential for academics and practitioners. The Chinese customer group in the Korean mobile payment market is one of the largest undeveloped markets, offering a unique research opportunity. Therefore, we focused on the differences between Chinese and Korean consumer income groups in intent to use mobile payments. Comparing these two consumer groups provided two representative findings. Firstly, in terms of the gaps in income level, purchasing power, and network quality, Chinese and Korean groups have unique and mutually different demographic characteristics. Secondly, Chinese users play the most critical role in online shopping. Since Chinese mobile payment use patterns are entirely different, Chinese consumers have less experience with Kakaopay than Korean consumers. Therefore, an empirical analysis of Chinese and Korean costumers can enhance our ability to analyze the factors influencing UI.

Compared with the three separate models, UTAUT, D\&M ISS, and TTF, we proposed an integrated model that combines their different advantages. Each of the three independent models has its own 
historical and perspective limitations. Therefore, it is necessary to conduct an appropriate discussion with the data from both Chinese and Korean groups from the perspectives of theoretical literature and practical solutions and to accurately detect the key elements influencing the Chinese users' usage intention in relation to the Korean m-payment system.

The integrated model in this research complemented several variables from the original UTAUT model. Performance expectancy (PE), effort expectancy (EE), social influence (SI), facilitating conditions (FC), and Usage intention (UI) were evaluated according to Venkatesh et al. [20] and related researches $[21,56]$. Furthermore, task characteristics (TAC), technology characteristics (TEC), and task-technology fit (TTF) were evaluated according to Zhou [8] and related research [42]. Other related researches $[14,50]$ were utilized to evaluate system quality (SQ), information quality (IQ), service quality (SQ), and user satisfaction (US).

From a theoretical perspective, previous research on mobile payment technology in Korea [76-78] failed to integrate the TTF model into UTAUT, and DeLone and McLean's ISS, decreasing the explanatory power of their analyses. We empirically tested the influence effects of three qualities on UI, in addition to the impact of TTF on UI. UTAUT fully considers the characteristics of the operating system. TTF adopts a directly objective procedure by supposing that consumers use IT that offers benefits, but does not consider consumers' beliefs in and intents toward IT. DeLone and McLean's ISS considers the stability of the quality of the system. The imperfection of the models can be compensated for through their integrating.

Following the integration of the UTAUT and TTF, the empirical analysis results indicated a correlation between TTF and UTAUT constructs. The characteristics of task and technology significantly affect TTF, which significantly affect the performance expectancy, as well as the usage intention. With the integration between the UTAUT and D\&M ISS, we showed that SYQ, SQ, IQ, and PE are essential for consumer satisfaction, and SYQ, SQ, and IQ are critical for performance expectancy. Without the framework of the integrated model, we cannot analyze and identify the core factors influencing usage intention.

From the perspective of practical solutions, to stimulate the factors influencing usage intention, the integrated model provides a more comprehensive view to help mobile payment providers enhance their technological security advantages for improving costumers' UI.

According to the results in Table 8 , in the Chinese group, $\mathrm{PE}(\beta=0.277, p<0.01)$, SI $(\beta=0.301$, $p<0.01), \mathrm{FC}(\beta=0.347, p<0.01)$, and US $(\beta=0.332, p<0.01)$ significantly influenced UI, which is different from the Korean group, so it is necessary to stimulate these factors influencing the Chinese customers' UI. For example, performance expectancy significantly affects the Chinese customers' UI, and its effects follow the features that the Korean m-payment providers can offer $[79,80]$. The Korean m-payment providers should improve their services according to the Chinese users' demands to better satisfy the Chinese consumers' performance expectancy. However, compared with wired-network-based personal computer payment, the wireless m-payment network is more exposed to hacker attacks or error interception attacks [81], causing the Chinese consumers to worry about security and seriously affecting their PE. The Korean m-payment providers have a better digital encoding technique to provide a trustworthy and safe product, and offer customers a real-time service.

According to the construct of the integrated model in Figure 2, a good TTF is also an effective method for improving the Chinese consumers' performance expectancy. If the m-payment system cannot meet the Chinese customers' needs for payment tasks, they will assume that mobile payment technology is less practical, thus, creating low-performance expectations. For example, some mobile payment services may provide an ATM location service. Most Chinese consumers would accept these services as supporting technology. However, some users still complain that the service is insecure in terms of the disclosure of personal location information [82,83]. For these Chinese users, location services will create unacceptance of Korean mobile payment technology. Therefore, mobile payment technology providers need to obtain Chinese users' permissions before providing location services. 
Besides the significant determinant of PE, three other factors (SI, FC, and US) also directly and positively affect the Chinese consumers' UI. The role of social impact (SI) is worthy of attention, and Korean mobile payment providers should use suggestions and comments from earlier Chinese consumers to stimulate public praise in subsequent Chinese customers [84]. To improve the facilitating conditions (FC), the providers should consider input difficulties and the negative impact of small-screen mobile terminals, which should be designed so that they are more available to the Chinese consumers. Considering user satisfaction (US), the Korean providers should launch marketing operations to strengthen the Chinese consumers' acquaintance with both mobile payment technology and usability. Gradually, Chinese consumers' feelings of satisfaction will be improved.

\subsection{Contribution}

\subsubsection{Theoretical Contribution}

In relation to Korean m-payments, we integrated three models, and, using Kakaopay users' experience as the moderating variables, simultaneously lay a solid foundation for follow-up research in academia. Our analysis results can help academics to understand which factors can significantly improve UI. The willingness of Kakaopay users can guide market development strategies for Kakaopay and other Korean mobile payment service providers.

This study integrated D\&M ISS and TTF into UTAUT to explain the m-payment UI. We found that D\&M and TTF not only directly influence UI, but also affect UI via user satisfaction and performance expectancy separately. Besides, the contributions of this study are two-fold: First, these results indicate that the integrated model offers more explanatory power for user acceptance than D\&M ISS, TTF, or UTAUT alone. Therefore, future empirical research should adopt an integrated perspective to test the usage willingness of any other m-payment system. We think that the overall integration aspect will provide more valuable insights than the view using a single model. Second, few studies have focused on potential Chinese adopters who are long-term residents in Korea; this is an aspect of mobile payment research that is entirely unexplored, and we add to the limited knowledge of $\mathrm{m}$-payment by testing moderating variables in combination with Chinese and Korean cultural factors. Third, this comparison method improves the effectiveness of testing several Chinese-Korean comparison scenarios to reveal specific new gaps in mobile payment research. The comprehensive approach outlined in this paper should be a suitable model for assessing technical factors. The impact of performance expectancy can be used as a foundation and an important starting point for future research [85].

\subsubsection{Managerial Contribution}

From a practical perspective, this research revealed that D\&M ISS, TTF, and UTAUT have a significant effect on the core influencing factors which will directly affect the Chinese and Korean consumers' willingness to use Korean mobile payment. We discovered that the task-technology fit has a considerable impact on performance expectancy. Therefore, Korean mobile payment providers must improve the adaptability of task technology. They can segment the consumer market and provide customized technology to foreign customers. For example, Chinese professional staff and part-time working student customers may focus more on the usage costs and functions, but Chinese travelers may show more anxiety about the dependability and accessibility of Korean international mobile payment transfers. Therefore, Korean mobile payment providers can provide a series of customized services to satisfy the task requirements of different groups, thereby increasing the willingness of Chinese customers to use mobile payments in Korea. Korean mobile payment operators can also improve the technical experience of mobile consumers, such as PE. This goal can be achieved by offering a friendly consumer interface to decrease the workload expectancy and enhance the UI.

Our results indicate that if Korean mobile payment providers want to increase potential adopters, they should also enhance the quality of the systems and information to increase consumer satisfaction. Notably, in the context of the current situation, Korean mobile payment providers prefer to think that 
the importance of assessing the system quality diminishes as the mobile payment system matures and stabilizes. Therefore, the match between system quality information quality and task technology strongly influences the usage intention through user satisfaction and PE, respectively. Because mobile payment transactions occur whenever and wherever possible, we recommend that Korean m-payment system operators should focus on improving the utilitarian impact of PE, SI, FC, and US in Korean mobile payment services; for example, increasing the system speed, shortening the system-down time, strengthening various functions, and personalizing customized information technology. Continuous updating of all information supporting mobile payment customers could improve the quality of information. Uncorrelated, imprecise, or untimely information could influence customers' satisfaction.

Considering the moderating effect of Chinese and Korean users' differences, firstly, facilitating conditions to the usage intention of Korean m-payment systems should be enhanced to attract people who think highly of independence and privacy, such as free Wi-Fi traffic and professional Chinese and Korean after-sales consultation, to overcome the hardware and software barriers to the use of Kakaopay by Chinese and Korean users. Secondly, when Kakaopay providers develop mobile payment technology capabilities, they need to balance the Chinese and Korean users' performance expectations of these features. They can enhance the product function according to customer feedback to better satisfy customers' performance expectancy. Third, Korean customers are more sensitive to user satisfaction, which seems to be an essential factor in the development of the willingness to use technology. However, for Chinese users who prefer personal goals, the red envelope reward mechanism in using mobile payment could be one of Kakaopay's supplier marketing tools. Fourth, Chinese and Korean users can accurately describe their convenience or other technical features in using Kakaopay features, or user-friendly features could be included in their promotional programs to accommodate different tasks.

Based on the above findings, we need to consider different perspectives to take advantage of factors affecting PE, satisfaction, and the ultimate intention to use mobile payment. To formulate a long-term strategy and sustainability, policymakers should develop action plans according to the elements influencing their customers. Addressing each factor that affects the willingness to use in this model will correspondingly benefit the willingness of users in China and Korea, and even cross-border e-commerce and economic cooperation across the Asia-Pacific region.

\subsection{Limitations and Future Work}

Our research has some limitations. Firstly, we assumed that the future use of mobile payment would increase, due to the improvement in the factors affecting the Chinese customers' intention to use Kakaopay. Therefore, a follow-up study needs to be conducted. Secondly, we only conducted this research for a Korean mobile payment provider. Although Kakaopay is a representative provider of the Korean m-payment industry, it does not cover every field of global mobile payment. To strengthen the systematization of this research, we look forward to comparing the results with those from different countries with large sample size and a wide variety of cultures. Thirdly, we integrated D\&M ISS and TTF into UTAUT to identify the factors influencing m-payment's usage intention. Future research should apply other theories, for example, the trustworthiness of TAM theory, to explore the impact of other elements.

Author Contributions: X.L. and R.W. contributed to research design, empirical analysis, manuscript writing; Y.-T.L. developed the original idea for the study; J.H. were responsible for data collection and research design; S.-C.C. conducted the methodology, data analysis and research design. All authors read and approved the final manuscript.

Funding: This research received no external funding.

Conflicts of Interest: The authors declare no conflict of interest. 


\section{Appendix A. Operational Definition}

Table A1. Definition of each construct.

\begin{tabular}{|c|c|c|c|}
\hline The & $y$ and Construct & Operation Definition & Source \\
\hline \multirow{4}{*}{ ISS } & System quality & Quality of a mobile payment system and technical aspects. & [50] \\
\hline & Information quality & $\begin{array}{l}\text { Quality of mobile payment's system information and } \\
\text { contents provided by a mobile payment system. }\end{array}$ & [50] \\
\hline & Service quality & $\begin{array}{l}\text { Measures of a new mobile operating system service in } \\
\text { terms of reliability, responsiveness, assurance, and } \\
\text { personalization. }\end{array}$ & [50] \\
\hline & User Satisfaction & Satisfaction degree with the mobile payment system. & [14] \\
\hline \multirow{3}{*}{ TTF } & Task characteristics & $\begin{array}{l}\text { Some critical aspects of user task requirements, including } \\
\text { ubiquitous account management, money transfer and } \\
\text { remittance, and real-time account information inquiry. }\end{array}$ & [8] \\
\hline & $\begin{array}{l}\text { Technology } \\
\text { characteristics }\end{array}$ & $\begin{array}{l}\text { Some critical aspects of mobile banking technology, } \\
\text { including ubiquity, immediacy, and security. }\end{array}$ & [8] \\
\hline & Task-technology fit & $\begin{array}{l}\text { The rational perspective of what new technology can do to } \\
\text { optimize a job. It is affected by the nature of the task and } \\
\text { the practicality of the technology to complete the task. }\end{array}$ & [42] \\
\hline \multirow{5}{*}{ UTAUT } & $\begin{array}{l}\text { Performance } \\
\text { expectancy }\end{array}$ & $\begin{array}{l}\text { The degree of improving travel efficiency by using a mobile } \\
\text { payment system thought of by users. }\end{array}$ & {$[20,21,56]$} \\
\hline & Effort expectancy & $\begin{array}{l}\text { The use degree of the mobile payment system experienced } \\
\text { by users. }\end{array}$ & {$[20,21,56]$} \\
\hline & Social influence & $\begin{array}{l}\text { The impact degree to which a consumer notices that } \\
\text { important others believe he should use mobile } \\
\text { payment system. }\end{array}$ & {$[20,56]$} \\
\hline & $\begin{array}{l}\text { Facilitating } \\
\text { conditions }\end{array}$ & $\begin{array}{l}\text { Whether any convenient conditions and various technical } \\
\text { supports are needed by a mobile payment system, which } \\
\text { are perceived by users. }\end{array}$ & {$[20,56]$} \\
\hline & Usage Intention & The reasons for using mobile payment. & [21] \\
\hline
\end{tabular}

\section{References}

1. Business Insider. Available online: https://www.businessinsider.com/chart-korean-exports-2013-3 (accessed on 13 March 2019).

2. Export.gov. Available online: https://www.export.gov/apex/article2?id=Korea-eCommerce (accessed on 29 August 2019).

3. Yonhap. Available online: https://en.yna.co.kr/view/AEN20190304011253320?section=search (accessed on 5 March 2019).

4. Statista. E-Commerce Report. 2019. Available online: https://www.statista.com/study/42335/ecommercereport/ (accessed on 15 April 2019).

5. Kakaocorp. Available online: https://www.kakaocorp.com/service/Kakaopay?lang=en (accessed on 21 February 2017).

6. Yonhap. Available online: https://en.yna.co.kr/view/AEN20190521005651320?section=search (accessed on 21 May 2019).

7. Kim, C.; Galliers, R.D.; Shin, N.; Ryoo, J.H.; Kim, J. Factors influencing Internet shopping value and customer repurchase intention. Electron. Commer. Res. Appl. 2012, 11, 374-387. [CrossRef]

8. Zhou, T.; Lu, Y.; Wang, B. Integrating TTF and UTAUT to explain mobile banking user adoption. Comput. Hum. Behav. 2010, 26, 760-767. [CrossRef]

9. Tam, C.; Oliveira, T. Understanding the impact of m-banking on individual performance: DeLone McLean and TTF perspective. Comput. Hum. Behav. 2016, 61, 233-244. [CrossRef]

10. Wu, R.Z.; Lee, J.Z. The Use Intention of Mobile Travel Apps by Korea- Visiting Chinese Tourists. J. Distrib. Sci. 2017, 15, 53-64. 
11. Srivastava, S.C.; Chandra, S.; Theng, Y.L. Evaluating the role of trust in consumer adoption of mobile payment systems: An empirical analysis. Commun. Assoc. Inform. Syst. 2010, 27, 561-588.

12. Dahlberg, T.; Mallat, N.; Ondrus, J.; Zmijewska, A. Past, present and future of mobile payments research: A literature review. Electron. Commer. Res. Appl. 2008, 7, 165-181. [CrossRef]

13. Shin, D.H. Understanding user acceptance of DMBin South Korea using the modified technology acceptance model. Inter. J. Hum. Comput. Int. 2009, 25, 173-198. [CrossRef]

14. GSMA. The Mobile Economy. 2019. Available online: https://www.gsma.com/r/mobileeconomy/ (accessed on 30 August 2019).

15. Wang, Y.; Lee, S. The effect of cross-border e-commerce on China's international trade: An empirical study based on transaction cost analysis. Sustainability 2017, 9, 2028. [CrossRef]

16. Gao, L.L.; Waechter, K.A. Examining the role of initial trust in user adoption of mobile payment services: An empirical investigation. Informat. Syst. Front. 2017, 19, 525-548. [CrossRef]

17. Chun, S.H. E-Commerce Liability and Security Breaches in Mobile Payment for e-Business Sustainability. Sustainability 2019, 11, 715. [CrossRef]

18. Son, I.; Kim, S. Mobile Payment Service and the Firm Value: Focusing on both Up- and Down-Stream Alliance. Sustainability 2018, 10, 2583. [CrossRef]

19. Liébana-Cabanillas, F. Determinants of mobile payment acceptance: A hybrid SEM-neural network approach. Technol. Forecast. Soc. Chang. 2018, 129, 117-130. [CrossRef]

20. Venkatesh, V.; Morris, M.G.; Davis, G.B.; Davis, F.D. User acceptance of information technology: Toward a unified view. MIS Q. 2003, 27, 425-478. [CrossRef]

21. Davis, F.D. Perceived usefulness, perceived ease of use, and user acceptance of information technology. MIS Q. 1989, 13, 319-340. [CrossRef]

22. Alshare, K.; Mousa, A. The moderating effect of espoused cultural dimensions on consumer's intention to use mobile payment devices. In Proceedings of the 25th International Conference on Information Systems (ICIS 2014), Auckland, New Zealand, 14 December 2014.

23. Chou, Y.H.D.; Li, T.Y.D.; Ho, C.T.B. Factors influencing the adoption of mobile commerce in Taiwan. Int. J. Mob. Commun. 2018, 16, 117-134. [CrossRef]

24. Lu, J.; Yu, C.S.; Liu, C.; Wei, J. Comparison of mobile shopping continuance intention between China and USA from an espoused cultural perspective. Comput. Hum. Behav. 2017, 75, 130-146. [CrossRef]

25. Yang, K.; Forney, J.C. The moderating role of consumer technology anxiety in mobile shopping adoption: Differential effects of facilitating conditions and social influences. J. Electron. Commer. Res. 2013, 14, 334-347.

26. Malaquias, R.F.; Hwang, Y. Mobile banking use: A comparative study with Brazilian and US participants. Int. J. Inf. Manag. 2019, 44, 132-140. [CrossRef]

27. Shaikh, A.A.; Karjaluoto, H. Mobile banking adoption: A literature review. Telemat. Inform. 2015, 32, 129-142. [CrossRef]

28. Palau-Saumell, R.; Forgas-Coll, S.; Sánchez-García, J.; Robres, E. User acceptance of mobile apps for restaurants: An expanded and extended UTAUT-2. Sustainability 2019, 11, 1210. [CrossRef]

29. Lin, K.Y.; Wang, Y.T.; Hsu, H.Y.S. Why do people switch mobile platforms? The moderating role of habit. Internet Res. 2017, 27, 1170-1189. [CrossRef]

30. Qasim, H.; Abu-Shanab, E. Drivers of mobile payment acceptance: The impact of network externalities. Inf. Sys. Front. 2016, 18, 1021-1034. [CrossRef]

31. DeLone, W.H.; McLean, E.R. Information systems success: The quest for the dependent variable. Inf. Sys. Res. 1992, 3, 60-95. [CrossRef]

32. Mohammadi, H. Investigating users' perspectives on e-learning: An integration of TAM and IS success model. Comput. Hum. Behav. 2015, 45, 359-374. [CrossRef]

33. Sharma, S.K.; Sharma, M. Examining the role of trust and quality dimensions in the actual usage of mobile banking services: An empirical investigation. Int. J. Inf. Manag. 2019, 44, 65-75. [CrossRef]

34. Goodhue, D.L.; Thompson, R.L. Task-technology fit and individual performance. MIS Q. 1995, 19, $213-236$. [CrossRef]

35. Lee, C.C.; Cheng, H.K.; Cheng, H.H. An empirical study of mobile commerce in insurance industry: Task-technology fit and individual differences. Decis. Support Syst. 2007, 43, 95-110. [CrossRef]

36. Tam, C.; Oliveira, T. Understanding mobile banking individual performance: The DeLone McLean model and the moderating effects of individual culture. Internet Res. 2017, 27, 538-562. [CrossRef] 
37. Gan, C.; Li, H.; Liu, Y. Understanding mobile learning adoption in higher education: An empirical investigation in the context of the mobile library. Electron. Libr. 2017, 35, 846-860. [CrossRef]

38. Oliveira, T.; Faria, M.; Thomas, M.A.; Popovič, A. Extending the understanding of mobile banking adoption: When UTAUT meets TTF and ITM. Int. J. Inf. Manag. 2014, 34, 689-703. [CrossRef]

39. Shih, Y.Y.; Chen, C.Y. The study of behavioral intention for mobile commerce: Via an integrated model of TAM and TTF. Qual. Quant. 2013, 47, 1009-1020. [CrossRef]

40. Cohen, G.A. Mobile-health tool use and community health worker performance in the Kenyan context a quasi-experimental post-test perspective. J. Health Inform. Afr. 2014, 2, 44-54.

41. Igbaria, M.; Tan, M. The consequences of information technology acceptance on subsequent individual performance. Inform. Manag. 1997, 32, 113-121. [CrossRef]

42. Oliveira, T.; Thomas, M.; Baptista, G.; Campos, F. Mobile payment: Understanding the determinants of customer adoption and intention to recommend the technology. Comput. Hum. Behav. 2016, 61, 404-414. [CrossRef]

43. Yen, D.C.; Wu, C.S.; Cheng, F.F.; Huang, Y.W. Determinants of users' intention to adopt wireless technology: An empirical study by integrating TTF with TAM. Comput. Hum. Behav. 2010, 26, 906-915. [CrossRef]

44. Sharma, S.K.; Gaur, A.; Saddikuti, V.; Rastogi, A. Structural equation model (SEM)-neural network (NN) model for predicting quality determinants of e-learning management systems. Behav. Inf. Technol. 2017, 36, 1053-1066. [CrossRef]

45. Zhou, T. An empirical examination of continuance intention of mobile payment services. Decis. Support Syst. 2013, 54, 1085-1091. [CrossRef]

46. Dwivedi, Y.K.; Kapoor, K.K.; Williams, M.D.; Williams, J. RFID systems in libraries: An empirical examination of factors affecting system use and user satisfaction. Int. J. Inf. Manag. 2013, 33, 367-377. [CrossRef]

47. Chatterjee, S.; Kar, A.K.; Gupta, M.P. Success of IoT in smart cities of India: An empirical analysis. Gov. Inf. Q. 2018, 35, 349-361. [CrossRef]

48. Veeramootoo, N.; Nunkoo, R.; Dwivedi, Y.K. What determines the success of an e-government service? Validation of an integrative model of e-filing continuance usage. Gov. Inf. Q. 2018, 35, 161-174. [CrossRef]

49. Petter, S.; DeLone, W.; McLean, E. Measuring information systems success: Models, dimensions, measures, and interrelationships. Eur. J. Inf. Sys. 2008, 17, 236-263. [CrossRef]

50. Delone, W.H.; McLean, E.R. The DeLone and McLean model of information systems success: A ten-year update. J. Manag. Inf. Sys. 2003, 19, 9-30.

51. Au, N.; Ngai, E.W.; Cheng, T.E. Extending the understanding of end-user information systems satisfaction formation: An equitable needs fulfilment model approach. MIS Q. 2008, 32, 43-66. [CrossRef]

52. Verkijika, S.F. Factors influencing the adoption of mobile commerce applications in Cameroon. Telemat. Inf. 2018, 35, 1665-1674. [CrossRef]

53. Lin, T.C.; Huang, C.C. Understanding knowledge management system usage antecedents: An integration of social cognitive theory and task technology fit. Inf. Manag. 2008, 45, 410-417. [CrossRef]

54. Lu, H.P.; Yang, Y.W. Toward an understanding of the behavioural intention to use a social networking site: An extension of task-technology fit to social-technology fit. Comput. Hum. Behav. 2014, 34, 323-332. [CrossRef]

55. Dishaw, M.T.; Strong, D.M. Extending the technology acceptance model with task-technology fit constructs. Inf. Manag. 1999, 36, 9-21. [CrossRef]

56. Venkatesh, V.; Thong, J.Y.; Xu, X. Consumer acceptance and use of information technology: Extending the unified theory of acceptance and use of technology. MIS Q. 2012, 36, 157-178. [CrossRef]

57. Jaradat, M.I.R.M.; Al Rababaa, M.S. Assessing key factor that influences on the acceptance of mobile commerce based on modified UTAUT. Int. J. Bus. Manag. 2013, 8, 102-112. [CrossRef]

58. Lee, J.; Kim, K.; Shin, H.; Hwang, J. Acceptance Factors of Appropriate Technology: Case of Water Purification Systems in Binh Dinh, Vietnam. Sustainability 2018, 10, 2255. [CrossRef]

59. Morosan, C.; DeFranco, A. It's about time: Revisiting UTAUT2 to examine consumers' intentions to use NFC mobile payments in hotels. Int. J. Hosp. Manag. 2016, 53, 17-29. [CrossRef]

60. Alalwan, A.A.; Dwivedi, Y.K.; Rana, N.P. Factors influencing the adoption of mobile banking by Jordanian bank customers: Extending UTAUT2 with trust. Int. J. Inf. Manag. 2017, 37, 99-110. [CrossRef]

61. Chuang, L.M.; Chen, P.C.; Chen, Y.Y. The determinant factors of travellers' choices for the pro-environment behavioral intention-integration theory of planned behavior, unified theory of acceptance, and use of technology two and sustainability values. Sustainability 2018, 10, 1869. [CrossRef] 
62. Vongjaturapat, S.; Chaveesuk, S.; Chotikakamthorn, N.; Tongkhambanchong, S. Analysis of factor influencing the tablet acceptance for library information services: A combination of UTAUT and TTF Model. J. Inf. Knowl. Manag. 2015, 14, 1550023. [CrossRef]

63. Fianu, E.; Blewett, C.; Ampong, G.; Ofori, K. Factors Affecting MOOC Usage by Students in Selected Ghanaian Universities. Educ. Sci. 2018, 8, 70. [CrossRef]

64. Im, I.; Hong, S.T.; Kang, M.S. An international comparison of technology adoption Testing the UTAUT model. Inf. Manag. 2010, 48, 1-8. [CrossRef]

65. Zhang, L.Y.; Zhu, J.; Liu, Q. A meta-analysis of mobile commerce adoption and the moderating effect of culture. Comput. Hum. Behav. 2012, 28, 1902-1911. [CrossRef]

66. O'Neil, B. Electronic surveys: How to maximize success. Nurse Res. 2014, 21, 24-26.

67. Bryman, A. Social Research Methods, 4th ed.; Oxford University Press: Oxford, UK, 2012.

68. Duffett, M.; Burns, K.E.; Adhikari, N.K.; Arnold, D.M.; Lauzier, F.; Kho, M.E.; Lamontagne, F. Quality of reporting surveys in critical care journals: A methodologic review. Crit. Care Med. 2012, 40, 441-449. [CrossRef]

69. Armstrong, J.S.; Overton, T.S. Estimating Nonresponse Bias in Mail Surveys. J. Mark. Res. 1977, 14, $396-402$. [CrossRef]

70. Hair, J.F.; Black, W.C.; Babin, B.J.; Anderson, R.E. Multivariate Data Analysis: A Global Perspective, 7th ed.; Pearson Education International: Swannanoa, NC, USA, 2010.

71. Nunnally, J.C. Psychometric Theory; McGraw Hill: New York, NY, USA, 1978.

72. Fornell, C.; Larcker, D.F. Evaluating structural equation models with unobservable variables and measurement error. J. Mark. Res. 1981, 18, 39-47. [CrossRef]

73. Bagozzi, R.P.; Yi, Y.; Phillips, L.W. Assessing construct validity in organizational research. Adm. Sci. Q. 1991, 36, 421-430. [CrossRef]

74. Anderson, J.C.; Gerbing, D.W. Structural equation modelling in practice. A review and recommended two-step approach. Psychol. Bull. 1988, 103, 411-423. [CrossRef]

75. Hooper, D.; Coughlan, J.; Mullen, M.R. Structural equation modeling: Guidelines for determining model fit. Electron. J. Bus. Res. Methods 2008, 6, 53-60.

76. Kuan, H.H.; Bock, G.W.; Vathanophas, V. Comparing the effects of website quality on customer initial purchase and continued purchase at e-commerce websites. Behav. Inf. Technol. 2008, 27, 3-16. [CrossRef]

77. Hahn, H.Y.K.; Kim, J. The effect of offline brand trust and perceived internet confidence on online shopping intention in the integrated multi-channel context. Int. J. Retail Distrib. Manag. 2009, 37, 126-141. [CrossRef]

78. Lu, H.P.; Yu-Jen Su, P. Factors affecting purchase intention on mobile shopping web sites. Internet Res. 2009, 19, 442-458. [CrossRef]

79. Carlsson, C.; Carlsson, J.; Hyvonen, K.; Puhakainen, J.; Walden, P. Adoption of mobile devices/servicessearching for answers with the UTAUT. In Proceedings of the 39th Annual Hawaii International Conference on System Sciences (HICSS'06), Kauia, HI, USA, 4-7 January 2006; pp. 132-142.

80. Park, J.; Yang, S.; Lehto, X. Adoption of mobile technologies for Chinese consumers. J. Electron. Commer. Res. 2007, 8, 196-206.

81. Crabbe, M.; Standing, C.; Standing, S.; Karjaluoto, H. An adoption model for mobile banking in Ghana. Int. J. Mob. Commun. 2009, 7, 515-543. [CrossRef]

82. Junglas, I.; Abraham, C.; Watson, R.T. Task-technology fit for mobile locatable information systems. Decis. Support Sys. 2008, 45, 1046-1057. [CrossRef]

83. Sheng, H.; Nah, F.F.H.; Siau, K. An experimental study on ubiquitous commerce adoption: Impact of personalization and privacy concerns. J. Assoc. Inf. Sys. 2008, 9, 344-376. [CrossRef]

84. Wiedemann, D.G.; Haunstetter, T.; Pousttchi, K. Analyzing the basic elements of mobile viral marketing-an empirical study. In Proceedings of the 7th International Conference on Mobile Business, Barcelona, Spain, 7-8 July 2008; pp. 75-85.

85. Zhou, T. Understanding the determinants of mobile payment continuance usage. Ind. Manag. Data Sys. 2014, 114, 936-948. [CrossRef]

(C) 2019 by the authors. Licensee MDPI, Basel, Switzerland. This article is an open access article distributed under the terms and conditions of the Creative Commons Attribution (CC BY) license (http://creativecommons.org/licenses/by/4.0/). 